06

\title{
Моноокись кремния, карбонизированная фторуглеродом, как композитный материал для анодов литий-ионных аккумуляторов
}

\author{
() Д.А. Ложкина, Е.В. Астрова, А.И. Лихачев, А.В. Парфеньева, А.М. Румянцев, А.Н. Смирнов, В.П. Улин \\ Физико-технический институт им. А.Ф. Иофрфе, РАН \\ 194021 Санкт-Петербург, Россия \\ e-mail: darina.lozhka94@gmail.com
}

Поступило в Редакцию 26 марта 2021 г.

В окончательной редакции 23 апреля 2021 г.

Принято к публикации 24 апреля 2021 г.

\begin{abstract}
Дисперсные композитные материалы на базе моноокиси кремния и углерода $(\mathrm{SiO} / \mathrm{C})$ получены в результате термообработки смеси порошков, состоящей из $40 \mathrm{wt} \% \mathrm{SiO}$ и $60 \mathrm{wt} . \% \mathrm{CF}_{0.8}$. Отжиг производился в атмосфере аргона при температурах $1000-1250^{\circ} \mathrm{C}$. С помощью электронной микроскопии и комбинационного рассеяния света установлено, что при $T \geq 1100^{\circ} \mathrm{C}$ в твердофазном продукте появляется карбид кремния, в том числе в форме нановискеров кубической модификации. На основании данных об убыли веса реакционной смеси вычислен состав образующихся продуктов в зависимости от температуры отжига. Аноды, изготовленные из композитов, полученных при температуре выше $1100^{\circ} \mathrm{C}$, демонстрируют резкое падение емкости и кулоновской эффективности. Показано, что наблюдаемые изменения обусловлены не столько образованием $\mathrm{SiC}$, сколько возрастанием содержания кислорода в матрице, окружающей преципитаты кремния, которые образовались в результате диспропорционирования $\mathrm{SiO}$. Установлено, что оптимальной температурой отжига, обеспечивающей наиболее высокие значения емкости электродов, кулоновской эффективности первого цикла и способности работать при высоких плотностях тока, является $T=1050^{\circ} \mathrm{C}$.
\end{abstract}

Ключевые слова: монооксид кремния, карбонизация, вискеры карбида кремния, аноды для литий-ионных аккумуляторов.

DOI: $10.21883 /$ JTF.2021.09.51218.83-21

\section{Введение}

Моноокись кремния $\mathrm{SiO}$ перспективна как альтернатива элементарному кремнию в составе анодных материалов для литий-ионных аккумуляторов. Присутствие в них $\mathrm{SiO}$ способствует длительному стабильному циклированию на больших токах при достаточно высокой емкости [1]. К недостаткам электродов на основе $\mathrm{SiO}$ следует отнести малую кулоновскую эффективность первого цикла и низкую электронную проводимость [2]. Для повышения кулоновской эффективности и электропроводности анодного материала используются различные варианты композитов $\mathrm{SiO}$ с углеродом $[3,4]$. Их изготавливают, смешивая порошки $\mathrm{SiO}$ с графитом, графеном, углеродными нанотрубками и т. П., или же в результате карбонизации $\mathrm{SiO}$ в процессе пиролиза органических соединений. При этом небезразлично, в какой форме углерод находится в композите (размер частиц и соотношение $s p^{2}$ - и $s p^{3}$-углеродных связей). В наших предыдущих работах для создания углеродсодержащих композитов на базе $\mathrm{Si}$ и $\mathrm{SiO}$ был предложен простой метод их карбонизации с использованием твердофазного фторуглерода CF [5-7]. При диссоциации $\mathrm{CF}$, начинающейся с $T \sim 450^{\circ} \mathrm{C}$, выделяются газообразные фториды углерода $C_{n} F_{m}$, экзотермически реагирующие с частицами $\mathrm{Si}$ или $\mathrm{SiO}$, в результате чего поверхность каждой из таких частиц покрывается слоем восстановленного углерода, а кремний и кис- лород переходят в газовую фазу в виде $\mathrm{SiF}_{4}, \mathrm{SiF}_{2}$ и СО $[6,8]$. При проведении этих процессов в инертной среде (Ar) из смесей порошков $\mathrm{CF}$ с $\mathrm{Si}$ или с $\mathrm{SiO}$ получаются достаточно однородные электропроводящие композиты $\mathrm{Si} / \mathrm{C}$ или $\mathrm{SiO} / \mathrm{C}$, обладающие пористой структурой. В случае $\mathrm{SiO} / \mathrm{C}$ композитных электродов важную роль играет наличие отклонений от стехиометрического состава моноокиси $\left(\mathrm{SiO}_{x}\right)$ и степень ее диспропорционирования. Диспропорционирование моноокиси кремния, т.е. последовательная перегруппировка в ней атомов кислорода и кремния, приводящая, в конечном счете, к сегрегации $\mathrm{Si}$ и $\mathrm{SiO}_{2}$ фазовых выделений, развивается при температурах выше $900^{\circ} \mathrm{C}$ [9]. Предварительное диспропорционирование $\mathrm{SiO}$, как компонента анодного материала $(d-\mathrm{SiO})$, обеспечивает снижение необратимых потерь начального цикла заряда/разряда аккумулятоpa $[4,10]$. Применительно к предлагаемому нами методу диспропорционирование $\mathrm{SiO}$ и ее фторуглеродная карбонизация могут совмещаться в едином технологическом процессе. Но, как оказалось, при высоких температуpax отжига, помимо формирования $d-\mathrm{SiO} / \mathrm{C}$ композита, дополнительным продуктом протекающих в системе процессов становится карбид кремния, в том числе и в форме нановискеров, преимущественно кубической модификации [8]. Нитевидные нанокристаллы $\mathrm{SiC}$, как показано в [11], также способны обратимо внедрять литий и обеспечивать устойчивое циклирование аккумуляторов [12]. 
$\mathrm{B}$ настоящей работе с помощью сканирующей электронной микроскопии (SEM) и комбинационного рассеяния света (КРС) исследовано влияние температуры отжига смеси моноокиси кремния и фторуглерода на состав образующихся композитов и на электрохимические характеристики изготовленных из них анодов.

\section{1. Эксперимент}

Исходным материалом служили коммерческий продукт моноокиси кремния марки ОСЧ (особо чистый) и фторид углерода состава $\mathrm{CF}_{0.8}$ (галополимер). Порошки $\mathrm{SiO}$ и $\mathrm{CF}_{0.8}$, взятые в соотношении 40 wt.\% $\mathrm{SiO}+60$ wt.\% $\mathrm{CF}_{0.8}$, перемешивались и протирались в агатовой ступке. Из полученной смеси при давлении $180 \mathrm{MPa}$ всухую (без связующих) прессовались таблетки диаметром $10 \mathrm{~mm}$ и толщиной $\sim 400 \mu \mathrm{m}$, которые отжигались затем в квазизамкнутом объеме графитовых кассет. Кассеты помещались в муфельную печь с кварцевой трубой, продуваемой аргоном высокой чистоты 99.998\% (ТУ 6-21-12-94) и нагретой до $400^{\circ}$ C. Далее осуществлялось медленное повышение температуры со скоростью $3.3^{\circ} \mathrm{C} / \mathrm{min}$ до температуры $800-1250^{\circ} \mathrm{C}$, выдержка в течение $1 \mathrm{~h}$ и охлаждение в течение 30 min на краю трубы в потоке Ar. Таким образом, карбонизация и диспропорционирование моноокиси кремния могли совмещаться в едином процессе отжига. Таблетки взвешивались до и после отжига, до отжига их масса составляла $\sim 60 \mathrm{mg}$, после $-21-28 \mathrm{mg}$. Данные об образцах приведены в табл. 1 .

Структура полученных композитов исследовалась методом SEM с помощью растрового электронного микроскопа JSM 7001F (JEOL, Япония).

Таблица 1. Номера образцов и температура их отжига

\begin{tabular}{c|c}
\hline № образца & $T,{ }^{\circ} \mathrm{C}$ \\
\hline $2 a$ & 1250 \\
$2 b$ & 1200 \\
$2 c$ & 1150 \\
$2 d$ & 1100 \\
$2 e$ & 1050 \\
$2 f$ & 1000
\end{tabular}

Измерения спектров КРС проводилось при комнатной температуре на спектрометре Horiba Jobin Yvon T64000 (пр-во Франция), оснащенном конфокальным микроскопом Olympus BX41 (пр-во Япония). Для возбуждения спектров КРС использовался твердотельный лазер с диодной накачкой Nd:YAG (Torus, Великобритания) с $\lambda_{e x}=532 \mathrm{~nm}$. Лазерный луч фокусировался на поверхности образца с помощью объектива $100 \cdot(\mathrm{NA}=0.9)$ в пятно диаметром $\sim 0.9-1 \mu \mathrm{m}$.

Электрохимические испытания проводились в двухэлектродных дисковых ячейках CR2032 с литиевым противоэлектродом и электролитом марки TC-E918 (Tinci, $\mathrm{KHP}), \mathrm{LiPF}_{6}$ в смеси EC/PC/DEC/EMC/PA (этиленкарбонат, пропиленкарбонат, диэтилкарбонат, этилметилкарбонат, пропилацетат). Влагосодержание электролита было определено с помощью кулонометрического титратора Mettler Toledo С20 и составляло $22 \mathrm{ppm}$. Гальваностатические измерения выполнялись на стенде CT3008W-5V10mA (Neware, KНP). Напряжение на электроде ограничивалось $10 \mathrm{mV}$ при заряде (внедрении лития) и $2 \mathrm{~V}$ при разряде (экстракции лития).

\section{2. Результаты эксперимента и обсуждение}

\section{1. Вискеры SiC}

Внешний вид таблеток после термообработки при разной температуре дставлен на рис. 1. Хорошо видно, что при $T \geq 1150^{\circ} \mathrm{C}$ на поверхности образцов появляется голубой налет, который, как было показано в [8], образован вискерами $\beta$-SiC, кристаллизующимися из газовой фазы.

SEM-изображения образовавшихся нитевидных кристаллов $\mathrm{SiC}$ показаны на рис. 2. Видно, что с повышением температуры отжига вискеры $\mathrm{SiC}$ увеличиваются в диаметре и длине, тогда как сферические частицы, располагающиеся обычно на их концах (рис. 2, $d$ ), уменьшаются в размере. Присутствие таких частиц указывает на то, что кристаллизация наблюдаемых вискеров происходила с участием промежуточной жидкой фазы (по-видимому, силикатного расплава) по механизму пар-жидкость-твердое тело. По сравнению с внешней поверхностью таблеток в объеме твердофазного про-

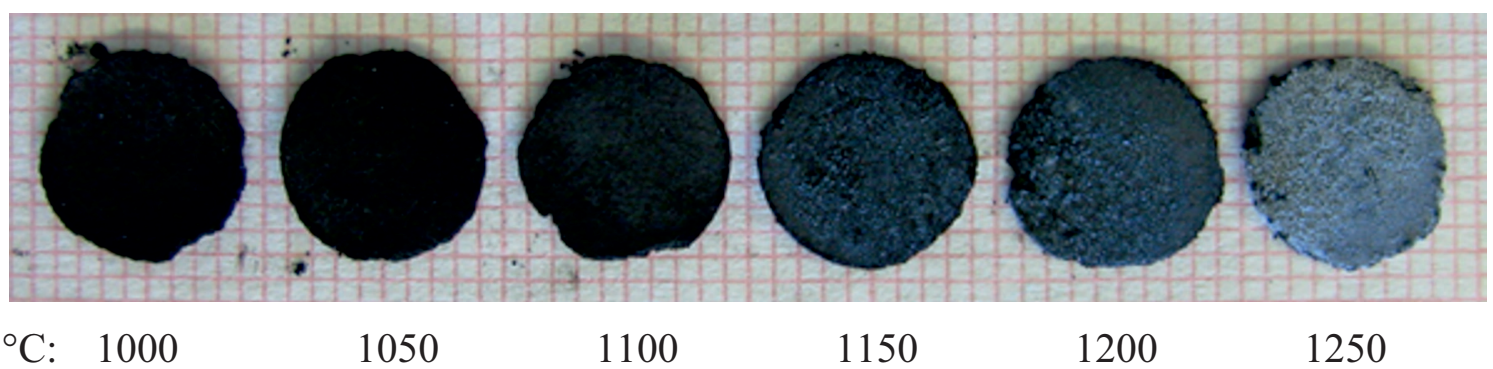

Рис. 1. Внешний вид таблеток $d-\mathrm{SiO} / \mathrm{C}$ с исходным составом $40 \mathrm{wt}$. $\mathrm{SiO}$ и $60 \mathrm{wt} . \% \mathrm{CF}_{0.8}$, отожженных при разной температуре. 


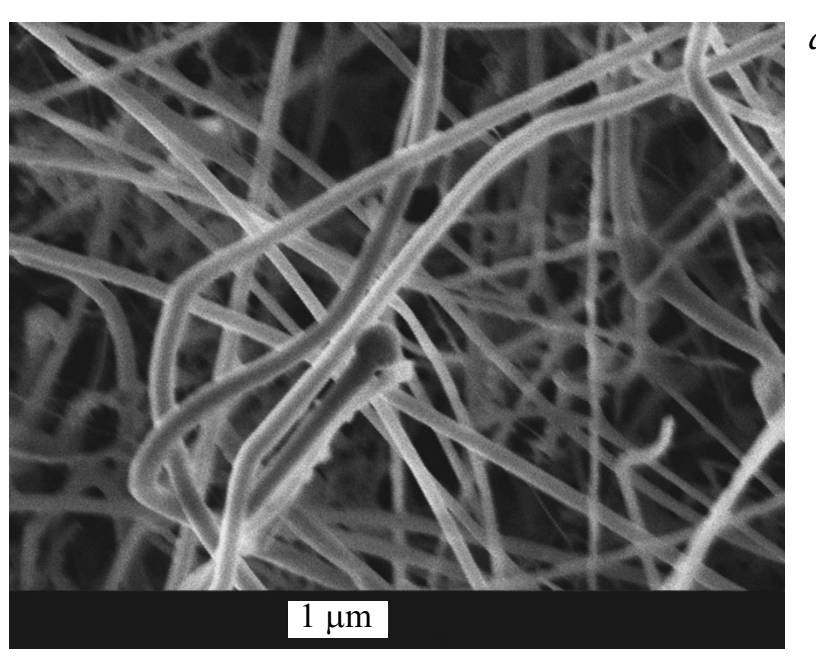

$1250^{\circ}$

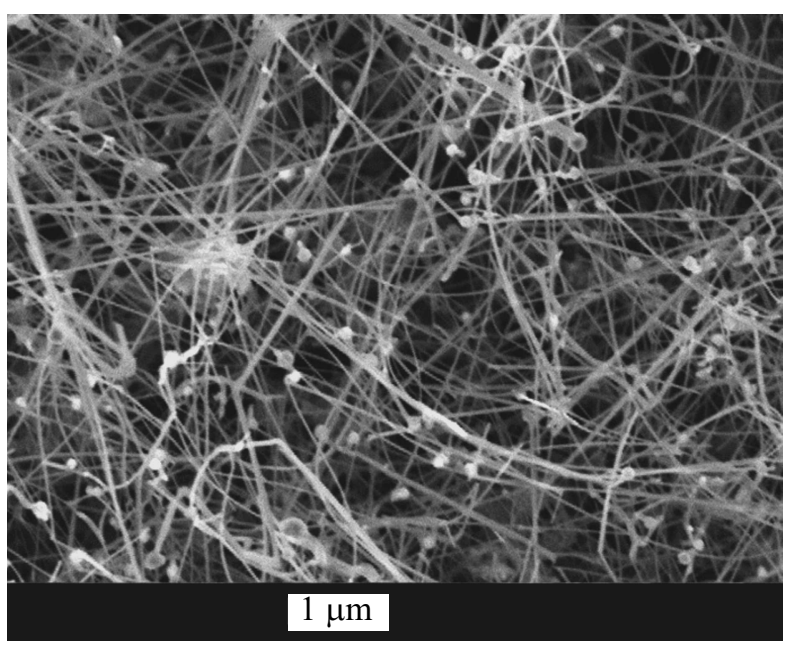

$1150^{\circ}$

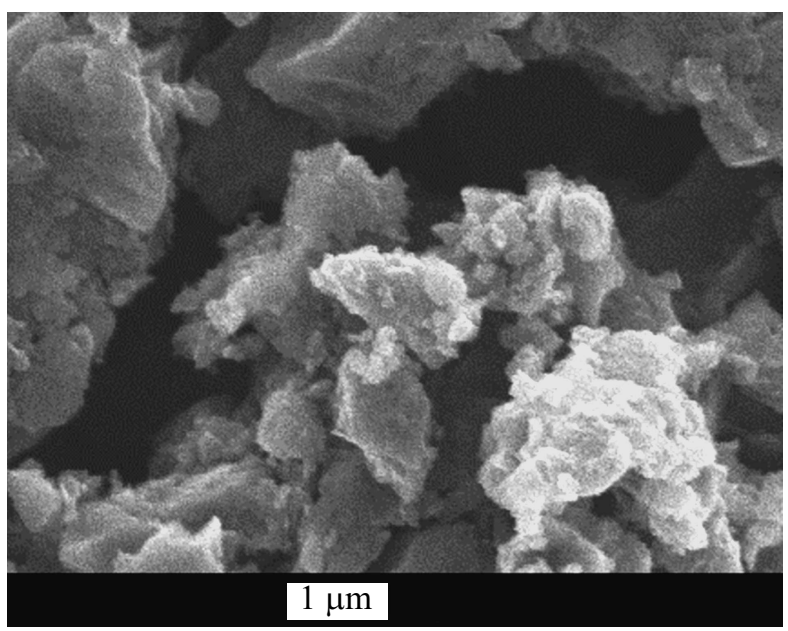

$1050^{\circ}$

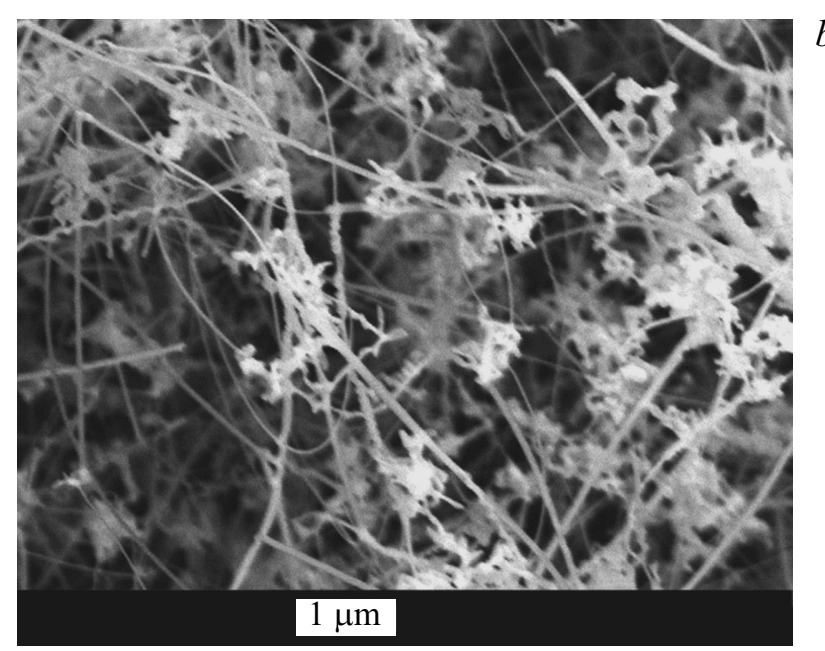

$1200^{\circ}$

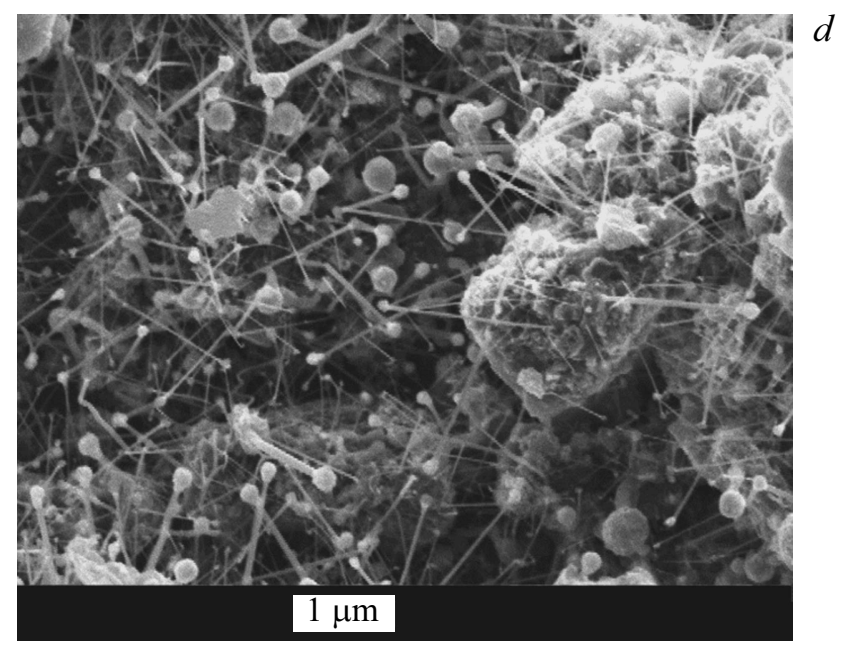

$1100^{\circ}$

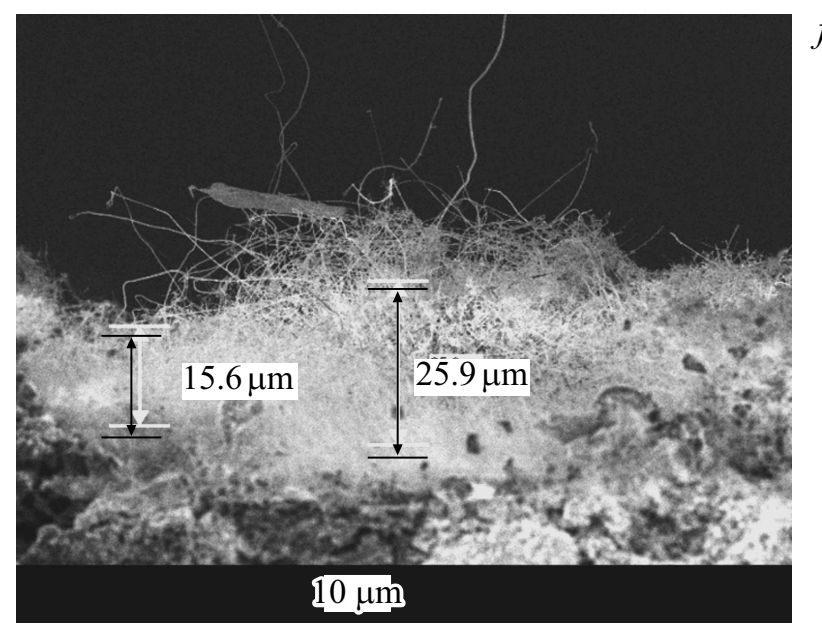

$1250^{\circ}$

Рис. 2. SEM-изображения поверхностей образцов после отжига при температурах: $a-1250, b-1200, c-1150, d-1100$, $e-1050^{\circ} \mathrm{C}, f-$ поперечное сечение образца $2 a$.

дукта вискеры $\mathrm{SiC}$ обнаруживаются редко, обычно в виде небольших скоплений внутри пор (не показаны). При наиболее высокой температуре $\left(1250^{\circ} \mathrm{C}\right)$ толщина непрерывного слоя, состоящего из вискеров $\mathrm{SiC}$, на поверхности образцов составила 15-30 $\mu$ m (рис. 2,f). $\mathrm{C}$ понижением температуры отжига области формирования $\mathrm{SiC}$ вискеров локализуются в отдельные неравномерно распределенные островки. 


\section{2. Количество образовавшегося карбида кремния}

На графике рис. 3 показано, как изменяется относительная потеря массы $\Delta m / m$ таблеток по мере увеличения температуры отжига.

Проанализируем фактическое изменение массы исходной смеси, происходящее за счет удаления газообразных продуктов реакции, и определим общее количество $\mathrm{SiC}$, образующегося при заданной температуре отжига (в любых формах). Химическое взаимодействие в смеси моноокиси кремния $\mathrm{SiO}$ и твердофазного фторуглерода $\mathrm{CF}_{0.8}$ начинается при $T \sim 450^{\circ} \mathrm{C}[8]$. Если температура не превышает $1000^{\circ} \mathrm{C}$, то суммарная реакция для совокупности происходящих в такой закрытой системе процессов может быть записана как

$$
\mathrm{SiO}+5 \mathrm{CF}_{0.8}=\mathrm{SiF}_{4} \uparrow+4 \mathrm{C}+\mathrm{CO} \uparrow .
$$

Тогда, чтобы $\mathrm{SiO}$ оставалась в конечном продукте, ее весовая доля в исходной смеси должна превышать $24.5 \%$. Обозначив через $r$ исходное содержание $\mathrm{CF}_{0.8}$ в весовых процентах и учитывая молекулярные массы компонентов реакции (1), их весовой баланс может быть представлен как:

$$
\begin{gathered}
(100-r) \mathrm{SiO}+r \mathrm{CF}_{0.8}=0.765 r \mathrm{SiF}_{4} \uparrow+0.206 r \mathrm{CO} \uparrow \\
+0.353 r \mathrm{C}+[100-1.324 r] \mathrm{SiO} .
\end{gathered}
$$

При более высоких температурах образование карбида кремния изменяет материальный баланс (2). В предельном высокотемпературном случае полной карбидизации остающегося в твердой фазе кремния:

$$
3 \mathrm{SiO}+5 \mathrm{CF}_{0.8}=2 \mathrm{SiC}+\mathrm{SiF}_{4} \uparrow+3 \mathrm{CO} \uparrow .
$$

В соответствии с реакцией (3) содержание $\mathrm{SiO}$ в исходной смеси может составлять до $49.25 \%$. В общем же случае, когда часть $\mathrm{SiO}$ расходуется в реакциях со фторидами углерода по схеме (1), а другая часть - по схеме (3) с образованием $\mathrm{SiC}$, полную реакцию можно представить как

$$
\begin{aligned}
(y+1) \mathrm{SiO}+5 \mathrm{CF}_{0.8}=y \mathrm{SiC} \\
\quad+\mathrm{SiF}_{4} \uparrow+(y+1) \mathrm{CO} \uparrow+(4-2 y) \mathrm{C},
\end{aligned}
$$

где $y<2$.

Тогда для произвольного содержания фторуглерода в исходной смеси $r$ в wt.\%, весовой баланс для компонентов реакции запишется как:

$$
\begin{gathered}
(100-r) \mathrm{SiO}+r \mathrm{CF}_{0.8}=0.294 y r \mathrm{SiC}+0.765 r \mathrm{SiF}_{4} \uparrow \\
+0.206(y+1) r \mathrm{CO} \uparrow+0.176(2-y) r \mathrm{C} \\
+[100-r(0.324 y+1.324)] \mathrm{SiO} .
\end{gathered}
$$

Из (5) находим, что

$$
\Delta m / m=r(0.971+0.206 y),
$$

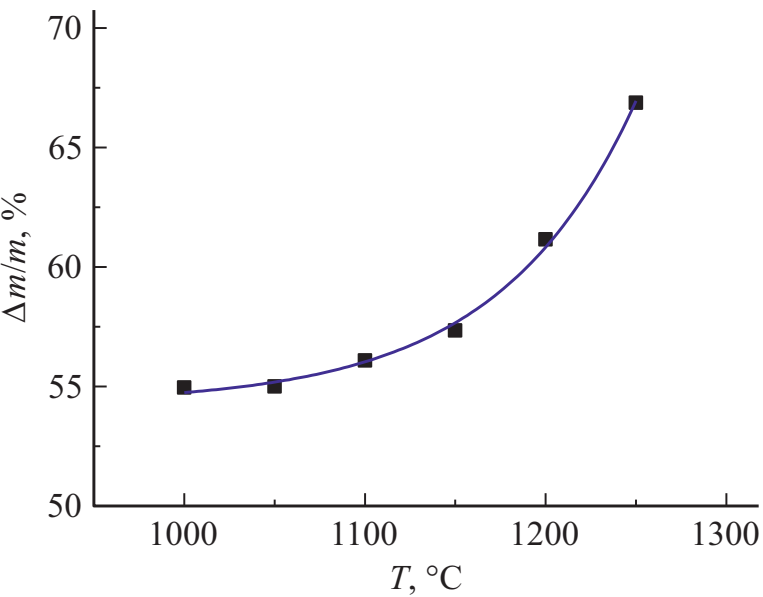

Рис. 3. Зависимость относительной потери массы таблеток от температуры отжига.

где $\Delta m$ - сумма весов летучих компонентов $\mathrm{SiF}_{4}$ и $\mathrm{CO}$. При этом, чтобы $\mathrm{SiO}$ оставалась в конечном продукте рассматриваемых превращений, квадратная скобка в (5) должна быть больше нуля. Следовательно, безотносительно температуры, при которой проходит реакция, $\mathrm{SiO}-$ содержащий композит может быть получен, если

$$
y<308.64 / r-4.086 .
$$

В нашем случае, когда в исходной смеси $r=60 \%$, получаем, что $y<1.058$.

Для достаточно низких температур, когда заведомо $y=0, \Delta m / m=0.971 r$, т.е. расчетное $\Delta m / m$ должно равняться $58.26 \%$. Сравнивая это ожидаемое изменение массы с экспериментально полученным при $1000^{\circ} \mathrm{C}$ значением $\Delta m / m=54.96 \%$, видим, что расчетная величина больше, чем найденная в эксперименте, в 1.06 раза. Причинами такого расхождения могут быть как неконтролируемый выход из камеры непрореагировавших газообразных фторидов углерода, так и отклонение от использованных для записи реакций стехиометрических коэффициентов в формулах исходных реагентов - моноокиси кремния и фторуглерода. Для лучшего согласования с расчетом соответствующая поправка может быть внесена в экспериментальные данные, как нормирующий коэффициент, т. е.

$$
\Delta m / m(\text { corr }) \approx 1.06 \Delta m / m .
$$

Тогда из (6) с учетом (8) получаем выражение для расчета $y$ :

$$
y \approx 0.086 \Delta m / m-4.71 .
$$

В табл. 2 приведены полученные значения у и вычисленный с их помощью состав твердой фазы образовавшегося композита.

Из табл. 2 видно, что в нашем случае даже при наиболее высокой температуре эксперимента карбида кремния образуется примерно в 2 раза меньше, чем в 
Таблица 2. Экспериментальные значения относительной потери массы смеси $40 \% \mathrm{SiO}+60 \% \mathrm{CF}_{0.8}$ в зависимости от температуры отжига, найденные из них величины выхода $\mathrm{SiC}(y)$ и соответствующий состав твердофазного продукта реакции

\begin{tabular}{c|c|c|c|c|c|c|c|c|c|c}
\hline $\begin{array}{c}\text { № } \\
\text { образца }\end{array}$ & $\begin{array}{c}T, \\
{ }^{\circ} \mathrm{C}\end{array}$ & $\begin{array}{c}\text { Эксперимент } \\
\Delta m / m, \%\end{array}$ & $\begin{array}{c}\text { После } \\
\Delta m / m \text { (соr),\% } \\
\text { корректировки }\end{array}$ & $y$ & $\begin{array}{c}\mathrm{SiC}, \\
\text { mol.\% }\end{array}$ & $\begin{array}{c}\mathrm{C}, \\
\text { mol.\% }\end{array}$ & $\begin{array}{c}\mathrm{SiO}, \\
\text { mol.\% }\end{array}$ & $\begin{array}{c}\mathrm{SiC}, \text { wt.\% } \\
\text { wt.\% }\end{array}$ & $\begin{array}{c}\mathrm{C}, \\
\text { wt.\% }\end{array}$ & $\begin{array}{c}\mathrm{SiO} \text { ' } \\
\text { wt.\% }\end{array}$ \\
\hline $2 a$ & 1250 & 66.87 & 70.9 & 1.04 & 35.0 & 64.5 & 0.6 & 63.6 & 35.3 & 1.1 \\
$2 b$ & 1200 & 61.15 & 64.8 & 0.55 & 13.9 & 73.2 & 12.9 & 27.6 & 44.0 & 28.4 \\
$2 c$ & 1150 & 57.34 & 60.8 & 0.22 & 4.8 & 77.0 & 18.2 & 10.0 & 48.3 & 41.8 \\
$2 d$ & 1100 & 56.09 & 59.5 & 0.11 & 2.4 & 78.0 & 19.6 & 5.0 & 49.5 & 45.6 \\
$2 e$ & 1050 & 55.30 & 58.6 & 0.05 & 0.9 & 78.6 & 20.4 & 2.0 & 50.2 & 47.8 \\
$2 f$ & 1000 & 54.96 & 58.3 & 0 & 0 & 79.0 & 21.0 & 0 & 50.7 & 49.3
\end{tabular}

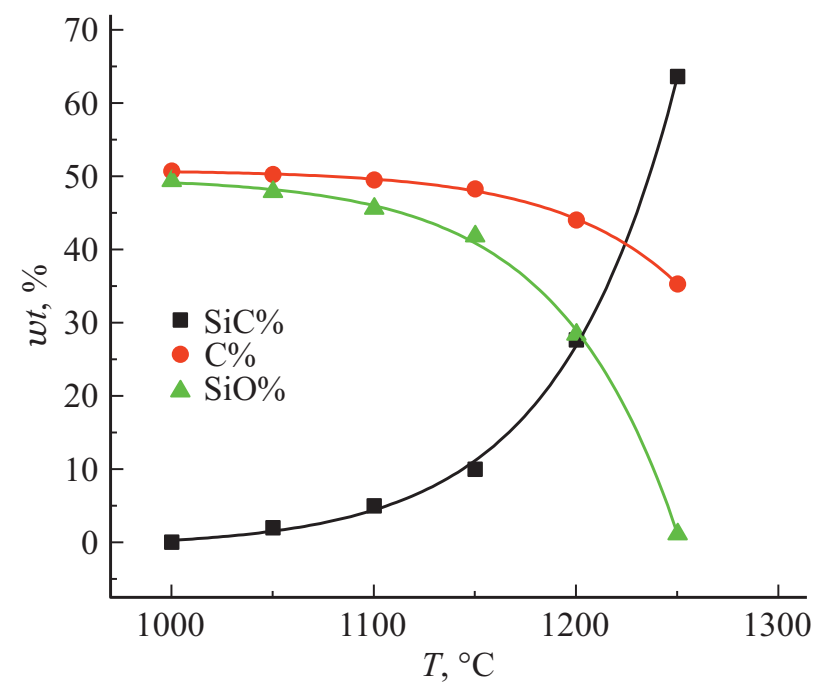

Рис. 4. Изменение количества карбида кремния, углерода и моноокиси кремния в твердофазном продукте реакции (4) в зависимости от температуры отжига. Состав исходной смеси 40 wt. $\% \mathrm{SiO}+60$ wt.\% $\mathrm{CF}_{0.8}$.

соответствии с реакцией (3), и при этом $\mathrm{SiO}$ все еще остается в конечном продукте. На рис. 4 показано, как изменяется с температурой процентное соотношение между веществами, остающимися в твердой фазе. Видно, что с увеличением температуры отжига, начиная с $1100^{\circ} \mathrm{C}$, количество образующегося $\mathrm{SiC}$ резко возрастает, а содержание $\mathrm{SiO}$ резко падает. При этом количество выделившегося углерода уменьшается менее заметно. В области $T<1050^{\circ} \mathrm{C}$, когда выход $\mathrm{SiC}$ пренебрежимо мал, исходная смесь $40 \% \mathrm{SiO}+60 \% \mathrm{CF}_{0.8}$ преобразуется в $\mathrm{SiO} / \mathrm{C}$-композит с практически одинаковой весовой долей компонентов.

\subsection{KPC}

Спектры КРС регистрировались в разных точках на поверхности таблетки. Разложение пиков на составляющие осуществлялось с помощью программы Fityk [13]. Форма пиков аппроксимировалась функцией Лоренца.
На рис. 5 представлены спектры КРС, полученные для образцов $2 a$ и $2 f$, отожженных при 1250 и $1000^{\circ} \mathrm{C}$ соответственно. В спектре образца $2 a$ (рис. $5, a)$ наблюдается три области: 500-1000 $\mathrm{cm}^{-1}$ (фононный спектр $\mathrm{SiC}$ ), $1000-2000 \mathrm{~cm}^{-1}$ (спектр первого порядка углерода, $\mathrm{C}(1))$ и $2300-3500 \mathrm{~cm}^{-1}$ (спектр второго порядка углерода, С (2)). В то же время в спектре КРС образца $2 f$ (рис. $5, b$ ) отсутствует область, связанная с фононным спектром $\mathrm{SiC}$ (аналогичные спектры были получены на образцах $2 c, 2 d$ и $2 e$, не показаны). Таким образом, данные спектроскопии КРС подтверждают результаты расчета о том, что при $T<1150^{\circ} \mathrm{C}$ карбид кремния образуется в незначительных количествах. Об этом же свидетельствует и исчезновение вискеров (рис. 1 и 2).

На рис. 6 представлено разложение спектров КРС образца $2 a$. Из этих спектров видно, что на поверхности образца присутствует карбид кремния (пики ТО $792 \mathrm{~cm}^{-1}$ и LO $932 \mathrm{~cm}^{-1}$ ). Ширина пика ТО на половине высоты FWHM $=25.86 \mathrm{~cm}^{-1}$, что согласуется с данными для вискеров $\mathrm{SiC}\left(22-31 \mathrm{~cm}^{-1}\right)$ [14]. Для объемного $\mathrm{SiC}$ характерны только 2 полосы TO и LO. В наших образцах на спектрах карбида кремния появляется третий пик $884 \mathrm{~cm}^{-1}$, который можно связать с наличием вискеров. В работах по исследованию вискеров $\beta$-SiC утверждается, что размерный эффект не влияет на спектр КРС, а влияют только структурные дефекты $[12,15,16]$. Так, в работе [15] в спектре КРС вискера $\mathrm{SiC}$ толщиной $40 \mathrm{~nm}$ наблюдался пик $842 \mathrm{~cm}^{-1}$, а в работах $[12,16]-$ пик $864 \mathrm{~cm}^{-1}$, который связывают с интерфейсной модой в нитевидных кристаллах $\mathrm{SiC}$ с множественными дефектами упаковки. Эти значения близки к наблюдавшимся нами в спектрах КРС образцов, отожженных при температурах 1200 и $1250^{\circ} \mathrm{C}\left(858-884 \mathrm{~cm}^{-1}\right)$.

В спектрах КРС образцов, отожженных в диапазоне $1000-1250^{\circ} \mathrm{C}$, наблюдаются полосы, которые идентифицируются как пики первого $\left(D, G, D_{2}, D_{3}\right)$ и второго порядка $\left(2 D, D+D_{2}\right)$ углерода $[17,18]$. При разложении спектров для образцов, отожженных при $T \leq 1200^{\circ} \mathrm{C}$, появляются еще один широкий пик первого порядка $D_{4}$ и один пик второго порядка $2 D_{2}$ (рис. 7).

Происхождение пиков КРС в графитоподобных пленках, полученных магнетронным распылением, подробно 

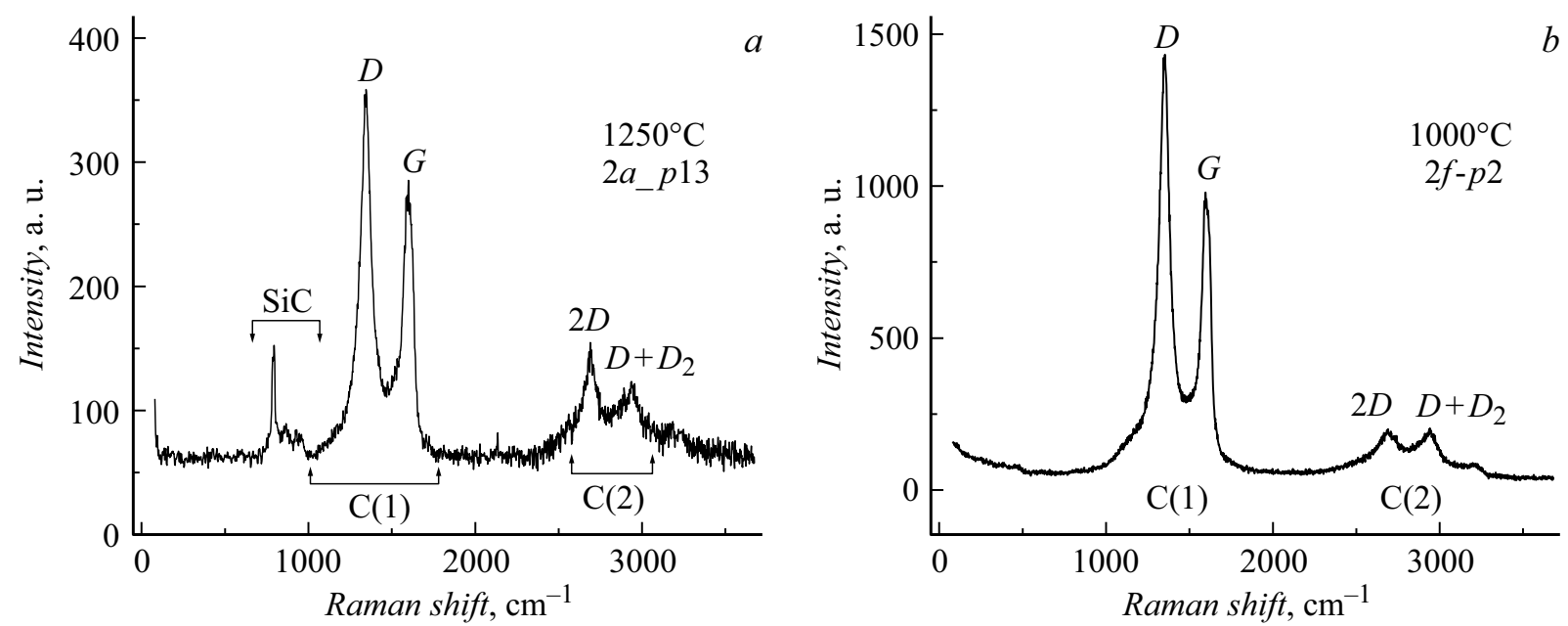

Рис. 5. Спектры КРС образцов, отожженных при 1250 (a) и $1000^{\circ} \mathrm{C}(b)$.
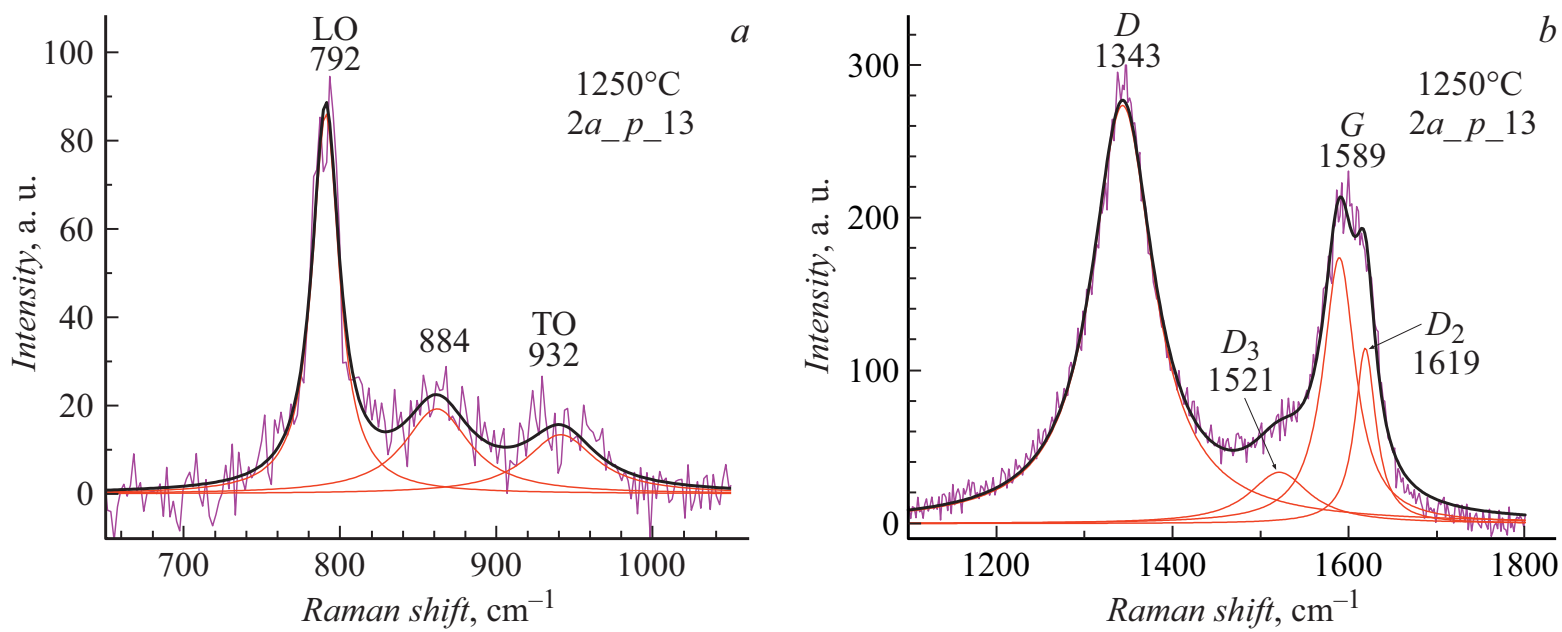

Рис. 6. Разложение на составляющие пики спектра КРС для образца $2 a$, отожженного при $1250^{\circ} \mathrm{C}$, в области: $a-\mathrm{SiC}, b-$ углерода (первый порядок КРС).
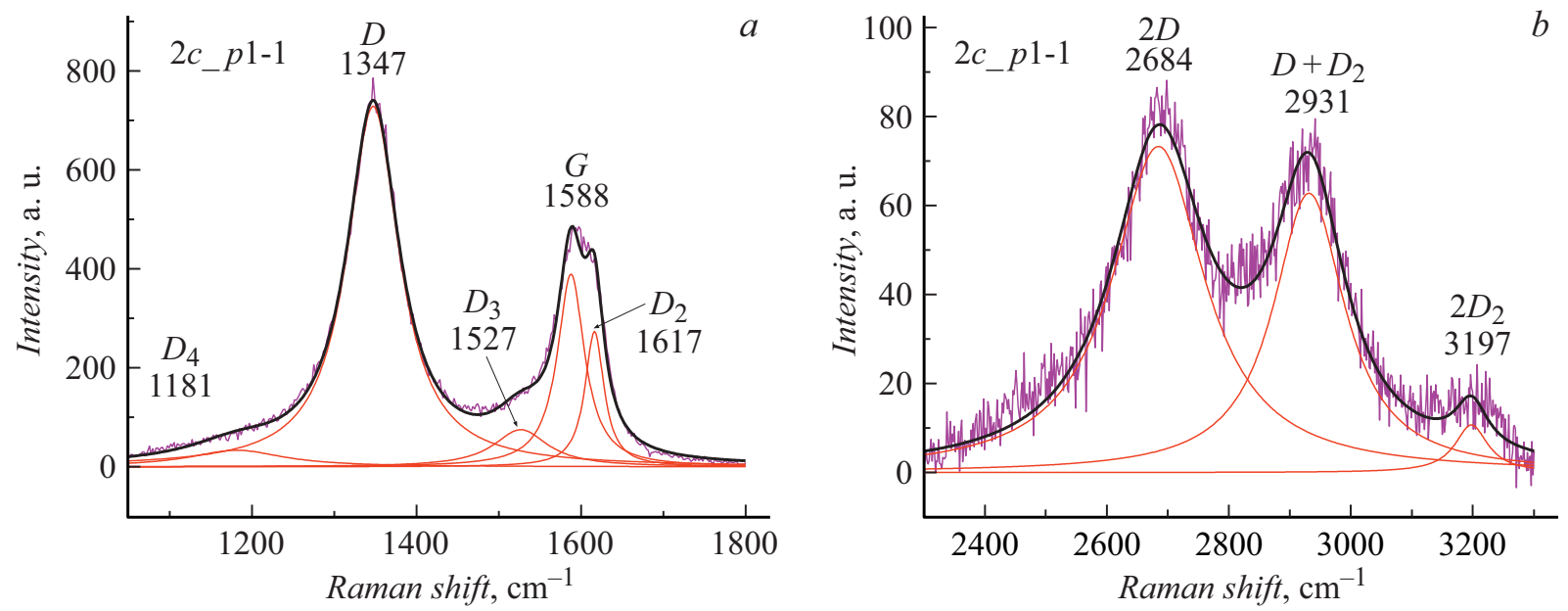

Рис. 7. Разложение на составляющие спектра КРС углерода в области первого $(a)$ и второго $(b)$ порядка для образца $2 c$, отожженного при $1150^{\circ} \mathrm{C}$. 

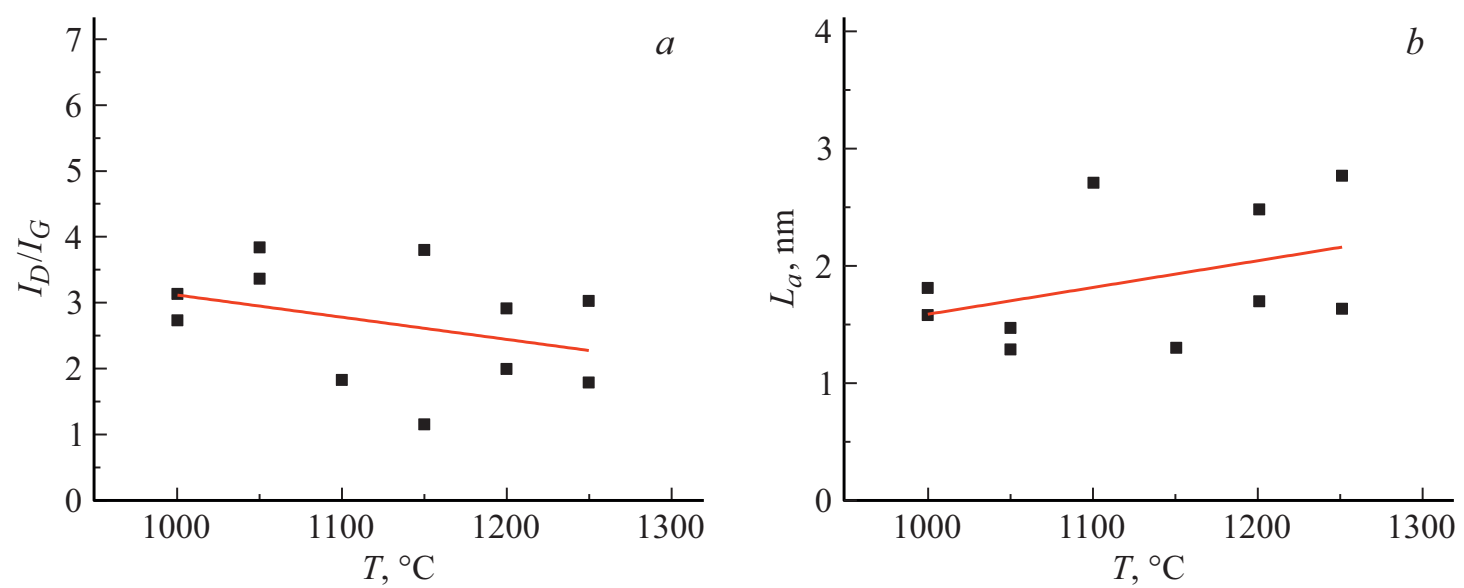

Рис. 8. Отношение интегральных интенсивностей пиков $D$ и $G(a)$ и соответствующих им латеральных размеров графитовых кластеров $(b)$ в зависимости от температуры отжига.
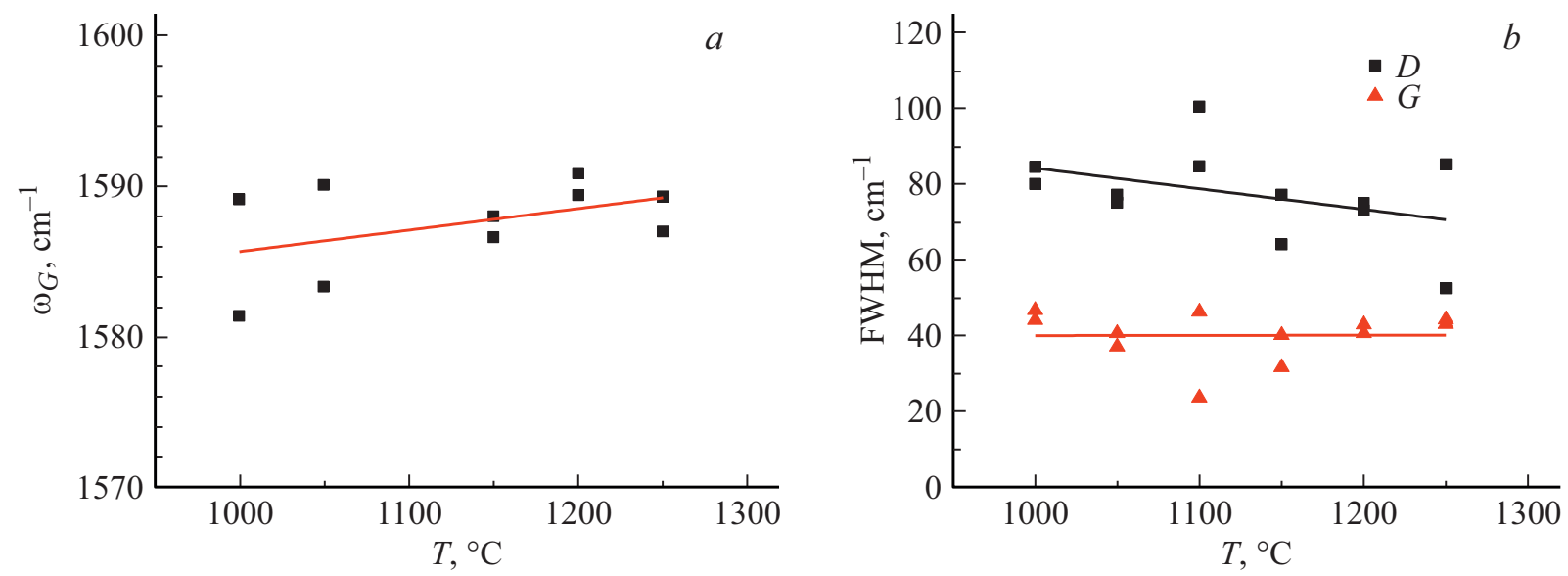

Рис. 9. Зависимость от температуры отжига: $a-$ спектрального положения пика $G, b-\mathrm{FWHM} \mathrm{пиков} D$ и $G$.

рассмотрено в работе [19]. $G$-пик обусловлен валентными колебаниями связей $s p^{2}$-гибридизованных атомов углерода в плоскости графенового слоя, а $D$-пик симметричными колебаниями образующих такой слой ароматических колец, как целого (дышашая мода). Для совершенных кристаллов графита $D$-мода оказывается запрещенной, но начинает проявляться при их разупорядочении, когда латеральные размеры совершенных участков графеновых слоев становятся ограниченными [20]. На рис. 8, a показана зависимость отношения интегральных интенсивностей полос $D$ и $G$ от температуры отжига $I_{D} / I_{G}$. Следует заметить, что измерения, которые, как правило, проводились для каждого из образцов в двух точках, обнаруживают довольно большой разброс данных. Тем не менее они указывают на тенденцию к снижению отношения $I_{D} / I_{G}$ с ростом температуры отжига (от $\sim 3.1$ до $\sim 2.3$ ). Можно ожидать, что повышение этой температуры ведет к прогрессирующему слиянию в более крупные кластеры графита отдельных, малых по размеру, группировок ароматических колец углерода, сформировавшихся непосредственно в ходе реакции $\mathrm{SiO}$ с фторуглеродами. Действительно, в полученных спектрах положение пика $\mathrm{G}$ находится в диапазоне, характерном для нанокристаллического графита, при энергиях, существенно больших, чем для аморфного углерода $\left(1520 \mathrm{~cm}^{-1}\right)$ [17] и даже немного сдвигается в сторону высоких частот по мере роста температуры отжига (рис. 9,a). Поэтому для определения латеральных размеров образовавшихся кластеров, $L_{a}$, мы использовали формулу Tuinstra-Koenig (TK) [21], справедливую для нанокристаллического графита $L_{a}=C\left(I_{D} / I_{G}\right)^{-1}$.

В работе [22] коэффициент $\mathrm{C}$ определен с учетом длины волны возбуждающего лазера $C=C_{0}+\lambda_{0} C_{1}$, где $C_{0}=-126 \AA, C_{1}=0.033 \AA, \lambda_{0}$ - длина волны возбуждающего лазера. В нашем случае $\lambda_{0}=5320 \AA$, что дает $C=49.56 \AA$. Результаты расчета приведены на рис. $8, b$. Видно, что $L_{a}$ проявляет тенденцию к возрастанию от $\sim 1.56$ до $\sim 2.17 \mathrm{~nm}$.

Как видно из рис. 9, $b$, FWHМ пика $G$, в отличие от пика $D$, практически не изменяется с температурой и составляет $\sim 40 \mathrm{~cm}^{-1}$. Так как $D$-мода связана с рассеянием, в котором участвуют дефекты кристаллической 

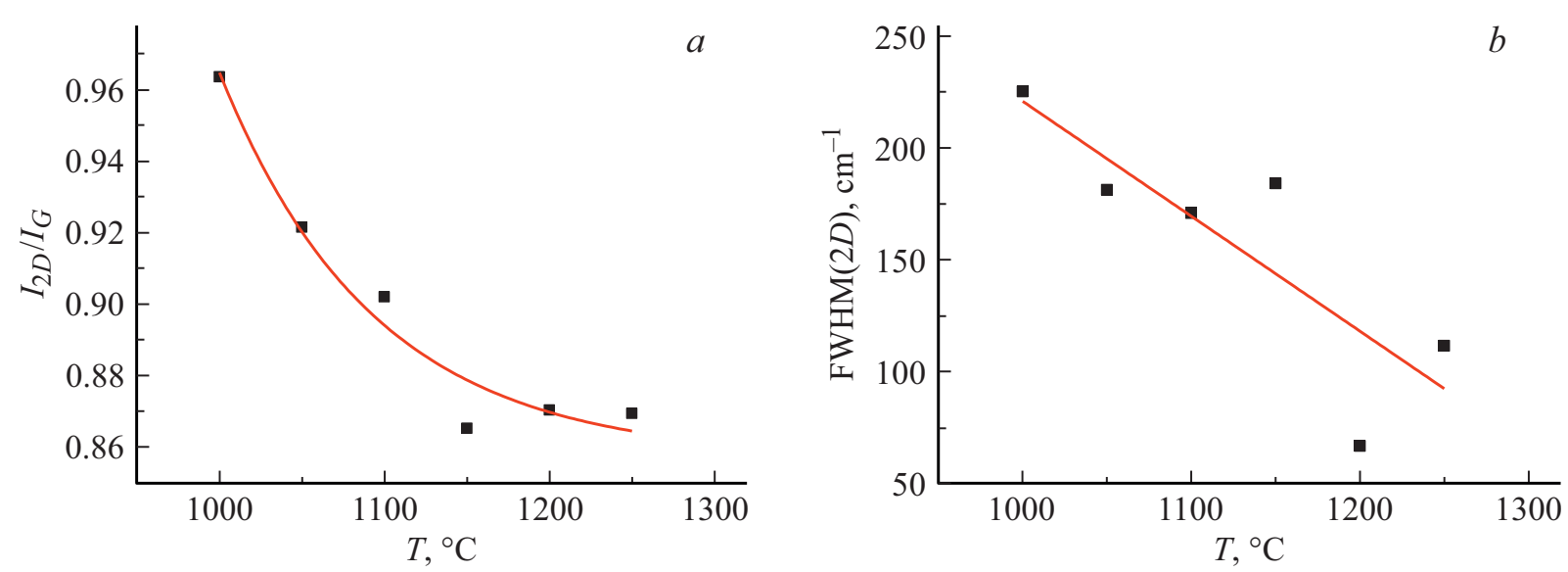

Рис. 10. Зависимость относительной интенсивности $I_{2 D} / I_{G}(a)$ и FWHM пика $2 D(b)$ от температуры отжига.

решетки, она более чувствительна к беспорядку, чем $G$-мода. Сужение соответствующей полосы с ростом температуры отжига (рис. 9, $b$ ) также свидетельствует об увеличении размеров кластеров графита. Полосы $D$ и $D_{2}$ обусловлены дефектами в графеновых слоях, а полосу $D_{3}$ связывают с присутствием аморфного углерода [18]. Что касается пика $D_{4}$ в виде низкоэнергетического плеча полосы $D$, то его появление характерно для очень дефектного материала [20]. В наших образцах он исчезает в спектрах КРС при температуре отжига $T=1250^{\circ} \mathrm{C}$.

Проанализируем полосы второго порядка. Полоса $2 D$ при $2700 \mathrm{~cm}^{-1}$, состоящая из одиночного пика, характерна для углеродного материала с преобладанием отдельных двумерных образований из гексагональных колец. В работе [23] при высокотемпературных $\left(2200-2700^{\circ} \mathrm{C}\right)$ отжигах различных саж отмечалось уменьшение ее интенсивности и появление двух новых пиков, один из которых связывают с трехмерным упорядочением. Наблюдаемое нами снижение $I_{2 D} / I_{G}$ с температурой (рис. 10,a), по-видимому, также можно связать с начальной стадией формирования областей с трехмерной структурой графита, что вместе с сужением пика $2 D$ от 220 до $100 \mathrm{~cm}^{-1}$ (рис. 10, b) свидетельствует о повышении степени структурного совершенства в образовавшихся углеродных кластерах.

Таким образом, наблюдавшиеся температурные изменения спектров КРС углерода, выделившегося при карбонизации $\mathrm{SiO}$, такие как снижение ширины полос $D$ и $2 D$, уменьшение отношений $I_{D} / I_{G}$ и $I_{2 D} / I_{G}$ свидетельствуют о возрастающей степени графитизации исследуемого материала $[18,23]$.

Следует отметить, что в спектрах КРС образцов, отожженных при температурах $1000-1150^{\circ} \mathrm{C}$, наблюдались очень слабые особенности в области частот $440-505 \mathrm{~cm}^{-1}$. Эти особенности могут быть приписаны колебаниям $\mathrm{SiO}$ [24]. Однако из-за малой эффективности рассеяния (по сравнению с эффективностью КРС в $\mathrm{SiC}$ и углеродном материале), регистрация этих особенностей была затруднительна.

\section{4. Электрохимические характеристики $\mathrm{SiO} / \mathrm{C}$-анодов}

Электрохимические характеристики анодов на базе полученных $\mathrm{SiO} / \mathrm{C}$-композитов исследовались при плотности тока $6.25 \mathrm{~mA} / \mathrm{g}$. На рис. 11 показаны зарядноразрядные кривые для 1-го и 10-го циклов, из которых видно, что высокотемпературный отжиг приводит к существенному изменению формы кривых и снижению емкости до значений менее $100 \mathrm{mAh} / \mathrm{g}$.

На рис. 12 показана температурная зависимость зарядной/разрядной емкости и кулоновской эффективности (СЕ) исследованных образцов.

Из рис. 12 видно, что емкость и СЕ первого цикла резко падают для образцов, отжигавшихся при $T>1100^{\circ} \mathrm{C}$. Можно предположить, что это обусловлено образованием карбида кремния в форме, непригодной для интеркаляции лития, как это наблюдалось в работе [7]. Для проверки этого предположения была использована двустадийная обработка $\mathrm{SiO}$, включающая предварительный отжиг при высоких температурах, с целью ее диспропорционирования, и последующую карбонизацию при $T=800^{\circ} \mathrm{C}$ в смеси с фторуглеродом. Для электрохимических испытаний из полученного композита $d-\mathrm{SiO} / \mathrm{C}$ изготавливались электроды по намазной технологии. Электродная масса составлялась в этом случае из: $88 \% d-\mathrm{SiO} / \mathrm{C}+5 \%$ сажа $+5 \% \mathrm{PVDF}+2 \%$ углеродные волокна VGCF. При этом с ростом температуры предварительного отжига $\mathrm{SiO}$ также отмечалось падение зарядной и разрядной емкостей, хотя при такой последовательности проведения процесса получения композита карбид кремния образоваться в нем не мог.

Для анализа причин снижения емкости при использовании высокотемпературного отжига $\mathrm{SiO}$ были опробованы порошки, подвергшиеся после карбонизации дополнительной обработке в НF. Как известно, при диспропорционировании $\mathrm{SiO}$ происходит выделение новой фазы нанокристаллического кремния, который может участвовать в реакции электрохимического литирования. Поскольку скорость растворения оксидов кремния в 

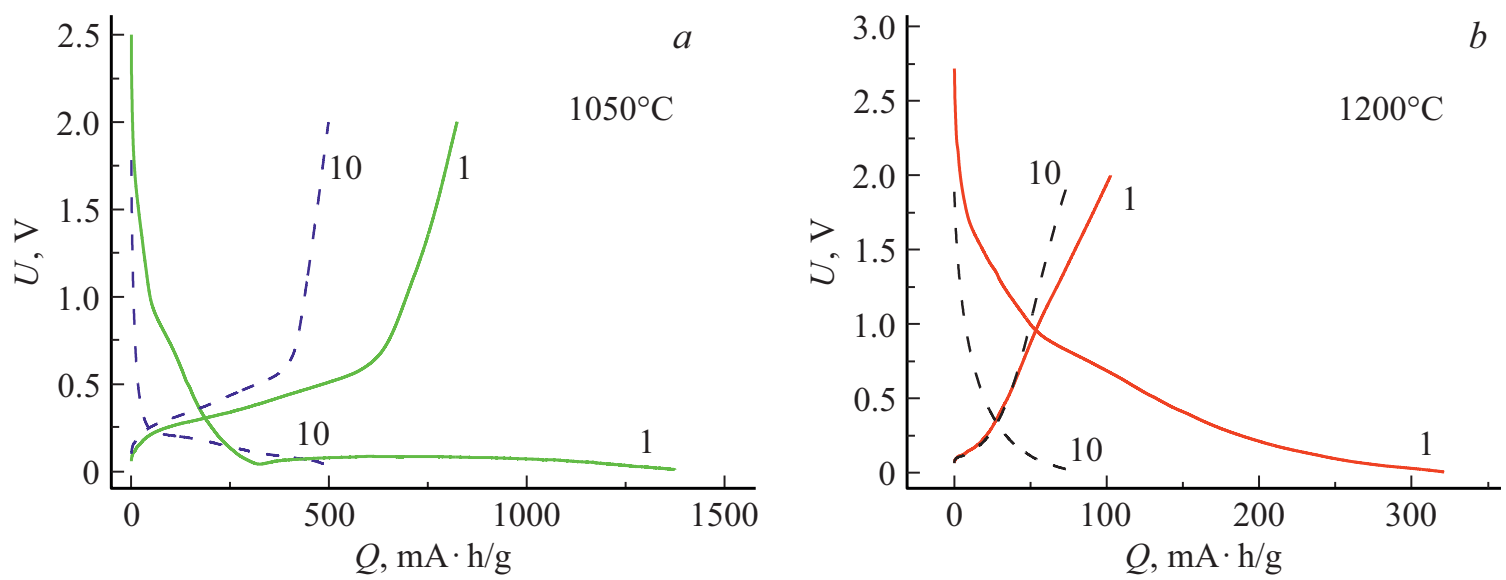

Рис. 11. Зарядно-разрядные кривые для 1-го и 10-го циклов для образцов, отжигавшихся: $a-$ при $1050, b-$ при $1200^{\circ} \mathrm{C}$.
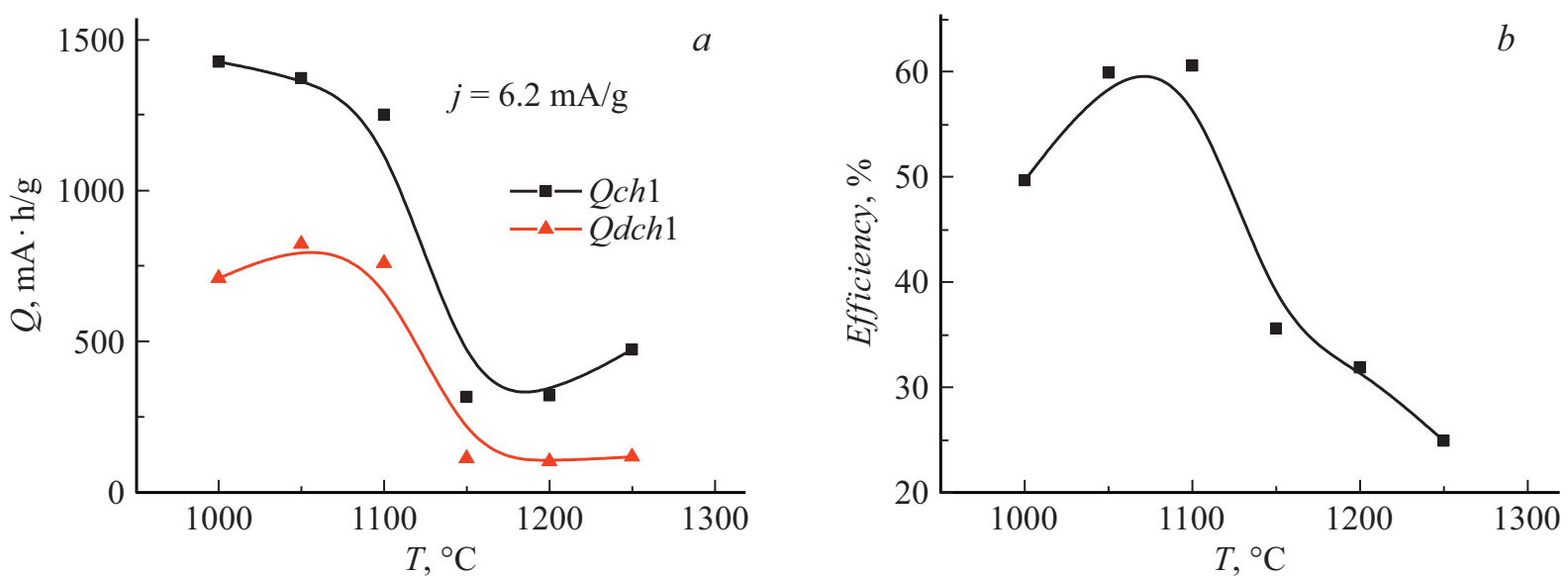

Рис. 12. Зависимость емкости заряда и разряда $(a)$ и кулоновской эффективности первого цикла $(b)$ от температуры отжига.

плавиковой кислоте на несколько порядков выше, чем самого кремния, удаление матрицы $\mathrm{SiO}_{x}$, окружающей преципитаты кремния, позволяет выявить роль $\mathrm{Si}$ в процессах заряда и разряда ячейки. Травление композита в смеси $\mathrm{HF}: \mathrm{H}_{2} \mathrm{O}(1: 1)$ проводилось в течение $2 \mathrm{~h}$, далее осуществлялась фильтрация, промывка деионизованной водой и спиртом. Полученный порошок $d-\mathrm{SiO} / \mathrm{C}(\mathrm{HF})$ использовался для изготовления анодов по намазной технологии, описанной выше. На рис. 13, a и $c$ приводятся зарядно-разрядные кривые 1-го цикла и зависимость разрядной емкости от номера цикла для анодов из композитов, полученных в двустадийном процессе при разной температуре первого этапа (диспропорционирования), включая отсутствующий первый этап (initial). На рис. $13, b, d$ показаны аналогичные зависимости для анодов из тех же порошков, но подвергшихся после карбонизации дополнительному травлению в НF.

Из рис. 13 видно, что после обработки в НF поведение композитов меняется на прямо противоположное. Если увеличение температуры диспропорционирования $\mathrm{SiO}$ приводит к падению емкости анодов на основе $\mathrm{d}-\mathrm{SiO} / \mathrm{C}$, то дополнительное травление композита в HF ведет к возрастанию емкости по мере того, как повышается температура предварительного отжига $\mathrm{SiO}$. Очевидно, что в последнем случае $\mathrm{SiO}_{x}$ матрица в частицах $d$ $\mathrm{SiO}$ должна содержать больше кислорода, приближаясь к $\mathrm{SiO}_{2}$. Это приводит к ее более эффективному растворению в НF. Образовавшиеся преципитаты кремния становятся доступнее для электролита и обеспечивают большую емкость электрода. Из табл. 3 видно, что кулоновская эффективность первого цикла для образцов $d$-SiO/C, обработанных в $\mathrm{HF}$, также возрастает, что, очевидно, связано с меньшими потерями, обусловленными необратимым образованием силикатов и оксидов Li.

В табл. 4 приведены данные из предыдущей работы [9] о количестве и размере кластеров $\mathrm{Si}$-фазы, а также о составе матрицы $\mathrm{SiO}_{x}$, формирующейся при диспропорционировании моноокиси кремния в том же температурном и временном режиме.

Кроме того, формирующееся при литировании силикатное окружение преципитатов кремния в $d-\mathrm{SiO}$ оказывается, по-видимому, более плотным и в большей степени ограничивает проникновение к кремнию ионов лития из электролита, нежели это происходит в частицах 

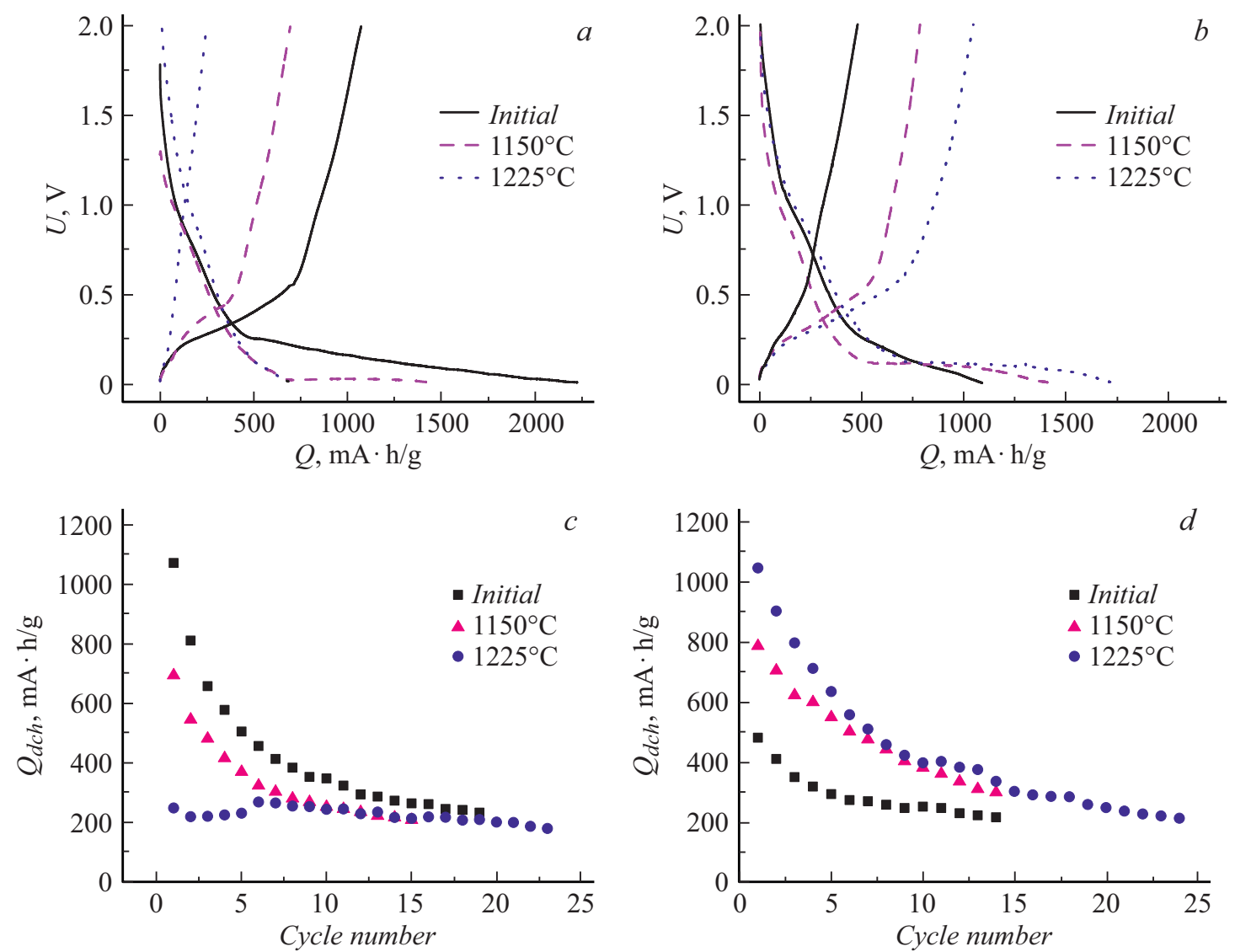

Рис. 13. Заряд/разрядные кривые 1-го цикла $(a, b)$ и зависимость разрядной емкости от номера цикла $(c, d)$ для композитных анодов с разной степенью диспропорционирования $\mathrm{SiO}$ до $(a, c)$ и после обработки их в $\mathrm{HF}(b, d)$. Плотность тока заряда и разряда $9 \mathrm{~mA} / \mathrm{g}$.

Таблица 3. СЕ первого цикла до и после обработки композитов в НF

\begin{tabular}{c|c|c}
\hline \multirow{2}{*}{$T,{ }^{\circ} \mathrm{C}$} & \multicolumn{2}{|c}{ СЕ, \% } \\
\cline { 2 - 3 } & После отжига & $\begin{array}{c}\text { После отжига и дополнительной } \\
\text { обработки в НF }\end{array}$ \\
\hline Initial & 48.2 & 44.1 \\
1150 & 48.1 & 54.9 \\
1225 & 35.6 & 60.4
\end{tabular}

$\mathrm{SiO}$, не подвергшихся предварительному отжигу. Следовательно, если присутствие $\mathrm{SiC}$ в композите и влияет на емкостные характеристики анодов, то это влияние не оказывается определяющим.

Таким образом, проведенные эксперименты показали, что повышения емкости и стабильности при циклировании анодов можно ожидать от $\mathrm{SiO} / \mathrm{C}$-композитов, изготовленных при $T<1100^{\circ} \mathrm{C}$ в условиях, когда $\mathrm{SiO}_{x}$ матрица, окружающая кремниевые преципитаты, остается при литировании еще достаточно проницаемой для ионов лития и когда карбид кремния еще не образуется.

Из табл. 2 и рис. 4 следует, что в области низких температур отжига исходной смеси $\left(T<1050^{\circ} \mathrm{C}\right)$, ко-
Таблица 4. Содержание кремниевых преципитатов (wt.\% Si), их диаметр $(D)$ и состав окружающей их матрицы субоксида $\mathrm{SiO}_{x}$ в зависимости от температуры отжига моноокиси кремния в $\mathrm{Ar}$ в течение $1 \mathrm{~h}$

\begin{tabular}{c|c|c|c}
\hline$T,{ }^{\circ} \mathrm{C}$ & $\mathrm{Si}, \mathrm{wt} . \%$ & $D, \mathrm{~nm}$ & $x$ в $\mathrm{SiO}_{x}$ \\
\hline Initial & 6.7 & 3.6 & 1.0 \\
800 & 10.3 & 3.3 & 1.1 \\
900 & 19.0 & 3.5 & 1.2 \\
1000 & 25.0 & 4.3 & 1.4 \\
1100 & 28.3 & 7.8 & 1.5 \\
1200 & 34.6 & 13.4 & 1.8
\end{tabular}

гда $y=0$, состав образующегося композита близок к 50 wt.\% $\mathrm{SiO}+50$ wt.\% С. Вследствие выделения в процессе карбонизации газообразных тетрафторида кремния и моноокиси углерода, такой твердофазный продукт разрыхляется, приобретая дополнительную пористость. Его интегральную пористость можно оценить как

$$
p=1-\rho_{\exp } / \rho_{\text {mix }}=57.7 \%,
$$

где $\rho_{\exp }=0.84 \mathrm{~g} / \mathrm{cm}^{3}-$ плотность таблетки после отжига, $\rho_{\text {mix }}=1.99 \mathrm{~g} / \mathrm{cm}^{3}-$ расчетная плотность компактной 
смеси, состоящей из равных массовых долей $\mathrm{SiO}$ и $\mathrm{C}, \mathrm{c}$ учетом того, что $\rho_{\mathrm{SiO}}=2.13 \mathrm{~g} / \mathrm{cm}^{3}, \rho_{\mathrm{C}}=1.86 \mathrm{~g} / \mathrm{cm}^{3}$.

\section{5. Влияние температуры термообработки на скоростные характеристики и СE}

Исследования скоростной способности анодов $d$ - $\mathrm{SiO} / \mathrm{C}\left(1050^{\circ} \mathrm{C}\right)$ проводились на таблетке толщиной $\sim 100 \mu \mathrm{m}$, изготовленной в одностадийном режиме при $T=1050^{\circ} \mathrm{C}$ (рис. 14). Первые 10 циклов испытаний проводились при одинаковой плотности тока заряда и разряда $10 \mathrm{~mA} / \mathrm{g}$. При этом кулоновская эффективность возросла до $98.5 \%$. Далее ток увеличивали, но оставляли одинаковым для заряда и разряда. Начиная с 16-го цикла, испытания проводились в режиме разных токов заряда и разряда (на рис. 14 плотности тока указаны соответственно как числитель и знаменатель). Для сравнения в таком же режиме проводились испытания образца, который карбонизировался при $T=800^{\circ} \mathrm{C}$ и не содержал $\mathrm{SiO}$, подвергшуюся диспропорционированию. Полученные результаты приведены также на рис. 14.

Из сравнения данных на рис. 14 видно, что отжиг при $1050^{\circ} \mathrm{C}$, когда происходит частичное диспропорционирование $\mathrm{SiO}$, приводит к росту абсолютного значения емкости $Q_{0}$, установившейся при токе $10 \mathrm{~mA} / \mathrm{g}$, по сравнению с образцом, отжигавшимся при низкой температуре $800^{\circ} \mathrm{C}$, когда диспропорционирования еще нет $\left(Q_{0}=717 \mathrm{mAh} / \mathrm{g}\right.$ по сравнению с $\left.Q_{0}=566 \mathrm{mAh} / \mathrm{g}\right)$. Для обоих образцов увеличение тока приводит к снижению емкости, но для 800-градусного образца это выражено сильнее. Например, для режима $j=25 / 50 \mathrm{~mA} / \mathrm{g}$ новая емкость 800-градусного образца составляет $57 \%$ от $Q_{0}$, а для 1050 -градусного $-74 \%$ от соответствующего этой температуре начального значения $Q_{0}$. При возвращении после 20-го цикла к току $10 \mathrm{~mA} / \mathrm{g}$ в обоих образцах емкость вновь поднимается до прежней величины $Q_{0}$, что свидетельствует об отсутствии необратимых изменений

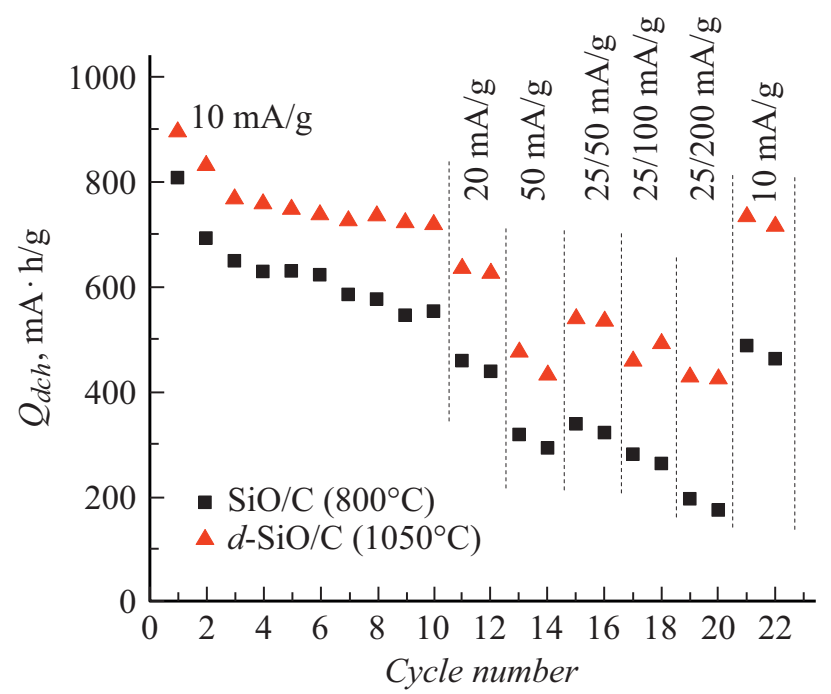

Рис. 14. Разрядная емкость анодов $\mathrm{SiO} / \mathrm{C}\left(800^{\circ} \mathrm{C}\right)$ и $d-\mathrm{SiO} / \mathrm{C}$ $\left(1050^{\circ} \mathrm{C}\right)$ при разных токах заряда/разряда.

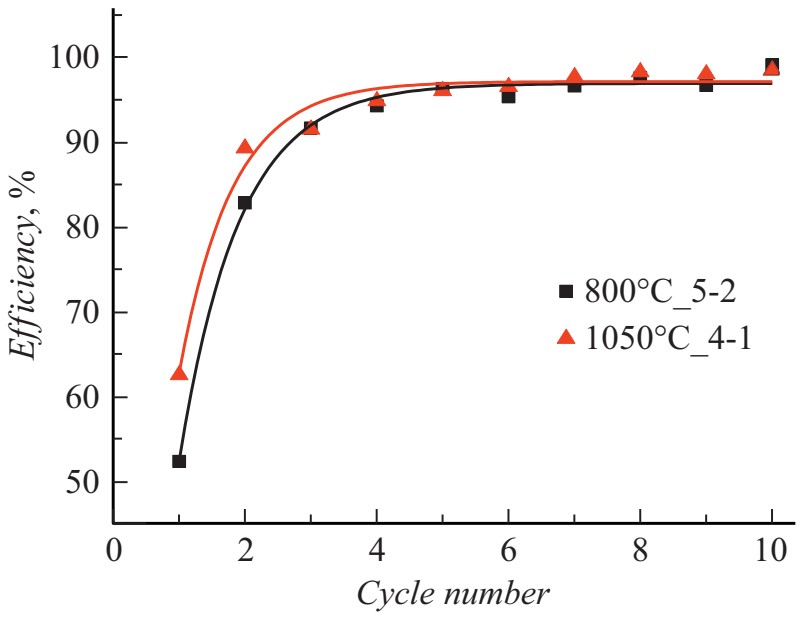

Рис. 15. СЕ-образцов, отожженных при разной температуре.

(разрушения) анодов при проведенном циклировании повышенными токами.

Диспропорционирование монооокиси кремния влияет и на кулоновскую эффективность. На рис. 15 показана зависимость кулоновской эффективности анодов из $\mathrm{SiO} / \mathrm{C}$ и $d-\mathrm{SiO} / \mathrm{C}\left(1050^{\circ} \mathrm{C}\right)$ от номера цикла, из которой видно, что оба образца характеризуются относительно низкой эффективностью в первом цикле, и постепенно возрастающей в последующих. Для 1050-градусного образца она выше: $62.5 \%$ против $52 \%$, и для него же выход на полочку происходит быстрее.

\section{Заключение}

Проведенные исследования показали, что

- получение композитов моноокиси кремния с углеродом путем отжига смеси $\mathrm{SiO}$ и $\mathrm{CF}_{0.8}$ может быть совмещено с диспропорционированием $\mathrm{SiO}$;

- при $T \geq 1100^{\circ} \mathrm{C}$ в продукте реакции образуется заметное количество карбида кремния, частично в виде нановискеров, размеры которых существенно изменяются с температурой;

- из экспериментальных данных об изменении массы образцов до и после отжига сделаны оценки количества $\mathrm{SiC}$, а также $\mathrm{C}$ и $\mathrm{SiO}$ в образовавшемся композите в зависимости от температуры термообработки. Согласно полученным данным для исходного состава $40 \mathrm{wt} . \%$ $\mathrm{SiO}+60$ wt.\% $\mathrm{CF}_{0.8}$, количество $\mathrm{SiC}$, образующееся при отжиге $1250^{\circ} \mathrm{C}$ в течение $1 \mathrm{~h}$, достигает $64 \mathrm{wt} . \%$;

- спектры КРС от образцов, полученных при $T>1100^{\circ} \mathrm{C}$, также свидетельствуют о присутствии в них $3 \mathrm{C}-\mathrm{SiC}$. Проявленный в указанных спектрах пик с максимумом $\sim 854 \mathrm{~cm}^{-1}$, подтверждает образование $\mathrm{SiC}$ в форме вискеров;

- из анализа спектров КРС композитов, полученных при $T=1000-1250^{\circ} \mathrm{C}$, следует, что образующийся углерод состоит из нанокристаллического графита с латераль- 
ным размером кластеров $\sim 2 \mathrm{~nm}$ и аморфного углерода. По мере увеличения температуры отжига наблюдается небольшое повышение степени графитизации углерода;

- карбонизация $\mathrm{SiO}$ с помощью фторуглерода позволяет получить аноды, которые характеризуются удельной гравиметрической емкостью, превышающей емкость углеродных анодов;

- удаление из $d-\mathrm{SiO} / \mathrm{C}$ композитов оксидной составляющей существенно улучшает емкостные характеристики полученных из них анодов;

- испытания показали, что высокие температуры отжига нежелательны для получения композитного анодного материала $\mathrm{SiO} / \mathrm{C}$, в то время как температуры вблизи $1050^{\circ} \mathrm{C}$, при которых происходит не только карбонизация, но и частичное диспропорционирование моноокиси кремния, способствуют повышению разрядной емкости, скорости заряда/разряда и эффективности первого цикла.

\section{Благодарности}

Электронно-микроскопические исследования выполнены с использованием оборудования федерального ЦКП „Материаловедение и диагностика в передовых технологиях“.

\section{Конфликт интересов}

Авторы заявляют, что у них нет конфликта интересов.

\section{Список литературы}

[1] K. Pan, F. Zou, M. Canova, Y. Zhu, J.-H. Kim. J. Power Sources, 413, 20 (2019). DOI: 10.1016/j.jpowsour.2018.12.010

[2] J. Park, S.S. Park, Y.S. Won. Electrochim. Acta, 107, 467 (2013). DOI: https://doi.org/10.1016/j.electacta.2013.06.059

[3] M. Yamada, A. Ueda, K. Matsumoto, T. Ohzuku. J. Electrochem. Soc., 158 (4), A417 (2011). DOI: $10.1149 / 1.3551539$

[4] T. Tan, P.-K. Lee, D.Y.W. Yu. J. Electrochem. Soc., 166 (3), A5210 (2019). DOI: 10.1149/2.0321903jes

[5] Е.В. Астрова, В.П. Улин, А.В. Парфеньева, В.Б. Воронков. Письма в ЖТФ, 45 (13), 29 (2019). DOI: http://dx.doi.org/10.21883/PJTF.2019.13.47954.17818 [E.V. Astrova, V.P. Ulin, A.V. Parfeneva, V.B. Voronkov. Tech. Phys. Lett., 45 (7), 664 (2019). DOI: http://dx.doi.org/10.1134/S1063785019070022]

[6] E.V. Astrova, V.P. Ulin, A.V. Parfeneva, A.M. Rumyantsev, V.B. Voronkov, A.V. Nashchekin, V.N. Nevedomskiy, Y.M. Koshtyal, M.V. Tomkovich. J. Alloy. Compd., 826, $154242(2020)$ DOI: http://dx.doi.org/10.1016/j.jallcom.2020.154242

[7] Е.В. Астрова, А.В. Парфеньева, А.М. Румянцев, В.П. Улин, М.В. Байдакова, В.Н. Неведомский, А.В. Нащекин. Письма в ЖТФ, 46 (3), 14 (2020). DOI: http://dx.doi.org/10.21883/PJTF.2020.03.48985.18067 [E.V. Astrova, A.V. Parfeneva, A.M. Rumyantsev, V.P. Ulin, M.V. Baidakova, V.N. Nevedomskii, A.V. Nashchekin. Tech. Phys. Lett., 46 (2), 114 (2020).

DOI: http://dx.doi.org/10.1134/S1063785020020042]
[8] Е.В. Астрова, В.П. Улин, А.В. Парфеньева, А.В. Нащекин, В.Н. Неведомский, М.В. Байдакова. ФТП, 54 (8), 753 (2020). DOI: http://dx.doi.org/10.21883/FTP.2020.08.49647.9402

[E.V. Astrova, V.P. Ulin, A.V. Parfeneva, A.V. Nashchekin, V.N. Nevedomskiy, M.V. Baidakova. Semiconductors, 54 (8), $900(2020)$.

DOI: http://dx.doi.org/10.1134/S1063782620080059]

[9] Д.А. Ложкина, Е.В. Астрова, Р.В. Соколов, Д.А. Кириленко, А.А. Левин, А.В. Парфеньева, В.П. Улин. ФТП, 55 (4), 373 (2021).

DOI: http://dx.doi.org/10.21883/FTP.2021.04.50743.9575

[D.A. Lozhkina, E.V. Astrova, R.V. Sokolov, D.A. Kirilenko, A.A. Levin, A.V. Parfeneva, V.P. Ulin. Semiconductors, 55 (4), 373 (2021). DOI: 10.1134/S1063782621040096]

[10] Ch.-M. Park, W. Choi, Y. Hwa, J.-H. Kim, G. Jeong, H.J. Sohn. J. Mater. Chem., 20, 4854 (2010). DOI: https://doi.org/10.1039/B923926J

[11] D. Sri Maha Vishnu, J. Sure, H.-K. Kim, R. Vasant Kumar, C. Schwandt. Energy Storage Mater., 26, 234 (2020). DOI: https://doi.org/10.1016/j.ensm.2019.12.041

[12] Y. Hu, X. Liu, X. Zhang, N. Wan, D. Pan, X. Li, Y. Bai, W. Zhang. Electrochim. Acta, 190, 33 (2016). DOI: https://doi.org/10.1016/j.electacta.2015.12.211

[13] M. Wojdyr. J. Appl. Cryst., 43 (5), 1126 (2010). DOI: https://doi.org/10.1107/S0021889810030499

[14] R. Dhiman, E. Johnson, P. Morgen. Ceram. Int, 37 (8), 3759 (2011). DOI: 10.1016/j.ceramint.2011.06.001

[15] M. Bechelany, A. Brioude, D. Cornu, G. Ferro, P. Miele. Adv. Funct. Mater., 17, 939 (2007). DOI: 10.1002/adfm.200600816

[16] S.-L. Zhang, B.-F. Zhu, F. Huang, Y. Yan, E.-Y. Shang, S. Fan, W. Han. Solid State Commun., 111, 647 (1999). DOI: https://doi.org/10.1016/S0038-1098(99)00262-8

[17] A. Merlen, J.G. Buijnsters, C. Pardanaud. Coatings, 7 (10), 153 (2017). DOI: https://doi.org/10.3390/coatings7100153

[18] A. Sadezky, H. Muckenhuber, H. Grothe, R. Niessner, U. Pöschl. Carbon, 43 (8), 1731 (2005). DOI: 10.1016/j.carbon.2005.02.018

[19] А.Я. Виноградов, С.А. Грудинкин, Н.А. Беседина, С.В. Коняхин, М.К. Рабчинский, Е.Д. Эйдельман, В.Г. Голубев. ФТП, 52 (7), 775 (2018). DOI: $10.21883 /$ JTF.2021.09.51218.83-21

[A.Y. Vinogradov, S.A. Grudinkin, N.A. Besedina, S.V. Koniakhin, M.K. Rabchinskii, E.D. Eidelman, V.G. Golubev. Semiconductors, 52 (7), 914 (2018). DOI: http://dx.doi.org/10.1134/S1063782618070266]

[20] A.C. Ferrari, J. Robertson. Phys. Rev. B, 61 (20), 14095 (2000). DOI: https://doi.org/10.1103/PhysRevB.61.14095

[21] F. Tuinstra, J.L. Koening. J. Chem. Phys., 53, 1126 (1970). DOI: https://doi.org/10.1063/1.1674108

[22] M.S. Dresselhaus, M.A. Pimenta, P.C. Eklund, G. Dresselhaus. In: Raman Scattering in Materials Science, ed. by W.H. Weber, R. Merlin (Springer-Verlag, Berlin, Heidelberg 2000), v. 42, c. 314.

[23] L.G. Cancado, K. Takai, T. Enoki, M. Endo, Y.A. Kim, H. Mizusaki, N.L. Speziali, A. Jorio, M.A. Pimenta. Carbon, 46, 272 (2008). DOI: https://doi.org/10.1016/j.carbon.2007.11.015

[24] T.P. Nguyen, S. Lefrant. Solid State Commun., 57 (4), 235 (1986). DOI: https://doi.org/10.1016/0038-1098(86)90146-8 